\title{
Estimation of parameters of elements of the technogenic landscape of the Degtyarsk post- exploitation zone with the use of unmanned aerial vehicles
}

\author{
Svetlana Elokhina $^{1}$, Alexey Kindler $^{2}$, and Ekaterina Afanasenko ${ }^{1}$ \\ ${ }^{1}$ Ural State Mining University, 620144, Ekaterinburg, Russia \\ ${ }^{2}$ FBGU "Hydrospetsgeology". Branch of the Ural Regional Center of the State Mining Inspectorate, \\ 620014, Ekaterinburg, Russia
}

\begin{abstract}
The article provides an example of the practical use of unmanned aerial vehicles as one of the methods for collecting geospatial data within the framework of state monitoring of the subsoil condition. The Degtyarsk post-exploitation zone was selected as the object under consideration.
\end{abstract}

\section{Introduction}

Earth remote sensing (ERS) technology is currently one of the most actively developing tendency of the geospatial data collection method. This method of collecting information has a number of positive features relative to many field methods of observations.

\section{Materials and methods}

The main positive feature of the use of ERS is the detail of the resulting material. For example, an image is a continuous series of points with information recorded in them (coordinates and absolute height), while in geodetic surveys the frequency of points is determined by the scale of the work being carried out (the distance between network points is measured in tens of meters). When plotting terrain from geodetic data, interpolation is used (adding intermediate values between the observed points) respectively, while for remote sensing data, the quality of the built terrain depends on the final scale of the desired map. In other words, it is possible to build a more detailed (with a small step of isolines) terrain of the territory without significant loss of quality due to a large number of data sources in the image. The second significant positive quality is the most realistic image of the area in comparison with maps and diagrams $[1,2,3]$.

The resulting images can be divided into three categories:

Space images (SI) - obtained with the use of aviation and space tools that have a large coverage of the territory ( $\mathrm{km} 2$ per image) and sufficient spatial resolution to assess the situation as a whole. 
Aerial photographs (AP) - obtained with the use of aircraft or helicopters that have a relatively smaller coverage of the territory than SI, but at the same time greater detail of the object being photographed. They are suitable for determining the boundaries and terrain of territories, studying the environment, etc.

Aerial photography, using small unmanned aerial vehicles (UAVs), have the smallest of the presented types of images coverage of the territory, with high detail of the object being filmed. This kind of digital photographic documentation is ideal for studying separate manifestations or objects.

In order to assess the place of each of the presented technologies among the existing methods of shooting, it is suggested to look at the chart shown in Fig.1. It also displays the technical parameters for each category of images. For monitoring purposes, the ideal tool is two of the technologies presented: SI for the development of survey routes, which are usually represented by free resources (Google and Yandex maps) and UAVs.

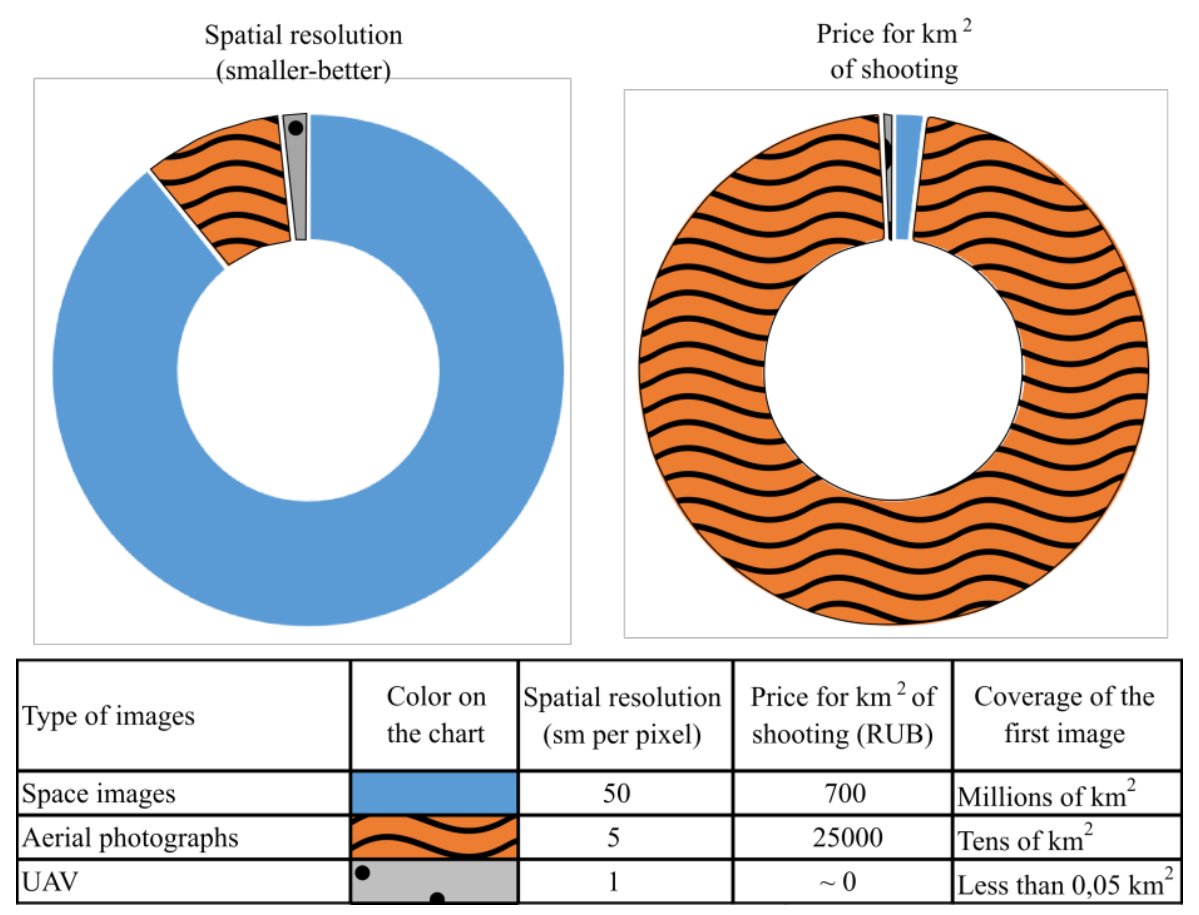

Fig. 1. The parameters for each category of images.

As can be seen from Figure 1, the use of UAVs is relevant in cases where it is necessary to quickly obtain accurate data on a small area of territory. The cost value of the resulting images at the initial stage of operation is equal to the cost of the aerial vehicle itself and the software package (Agisoft Metashape and Arcgis (QGIS, or any other GIS system [4]), but it is worth noting that the subsequent costs will be insignificant. Thus, having purchased a UAV and a complex for processing photographs, an organization can use it an unlimited number of times for an unlimited territory. Hence, the price of each subsequent image is reduced and eventually minimized, in contrast to aerial photographs, where each image will have a certain cost.

The images obtained from the UAV have a geographical reference, which allows not only to get a picture of the situation in the studied area, but also to perform a number of mathematical operations aimed at obtaining qualitatively new information. One of the 
simplest examples is the construction of situational maps of the territory, where a number of images obtained from UAVs are used as a geographical background. Another example is $3 \mathrm{D}$ models with the ability to calculate volumes or represent the same manifestation in an unlimited number of angles [5].

\section{Results and discussion}

Since 2019, within the framework of the state monitoring of the subsoil condition (SMSC), on the territory of the Ural Federal District in addition to traditional field methods of observations, research has included remote aerial photofixation of manifestations of dangerous exogenous geological processes (EGP) and individual manifestations of technogenesis using the Phantom-4 PRO unmanned aerial vehicle.

As part of the work on the assessment of hazardous EGP on the territory of the Sverdlovsk region, a survey of the Degtyarsk post-exploitation zone was performed. Due to the intensive mining activity, this area has had a significant impact of man-made processes on the environment. The territory of the mine at the end of mining and the termination of drainage measures is covered with a network of sinkholes and ditches of various sizes, quarry and sub-basement lakes, slagheaps (50-60 m high). The soil cover has not been restored everywhere and is characterized by low capacity.

Photofixation of individual manifestations was performed at various altitudes from 30 to $120 \mathrm{~m}$, depending on the size of the manifestations. The flight route itself was designed so that the resulting images were located directly above the linear object being photographed strictly vertically. The overlap for shooting from a UAV was about $60-80 \%$.

Due to the fact that all images are coordinate-bound, in the future it is possible to overlay them on different maps or images from previous years, which is especially important when evaluating changes in the size of a single image, combining one image from a series of images, building 3-D models and terrain isolines, morphometric profiles, etc. The total coverage area of a single image depended on the height of the shooting (Table 1).

Table 1. The area of coverage at different heights.

\begin{tabular}{|c|c|c|}
\hline $\begin{array}{c}\text { Height of the } \\
\text { camera above the } \\
\text { ground }(\mathrm{m})\end{array}$ & $\begin{array}{c}\text { Width of the projection image } \\
\text { of a single frame on the } \\
\text { ground }(\mathrm{m})\end{array}$ & $\begin{array}{c}\text { Height of the projection } \\
\text { image of a single frame on the } \\
\text { ground }(\mathrm{m})\end{array}$ \\
\hline 120 & 210 & 157,5 \\
\hline 70 & 122,5 & 91,875 \\
\hline 30 & 52,5 & 39,375 \\
\hline
\end{tabular}

Building a 3-D model allows you not only to visually display the situation on the territory, but also to present one and the same object (manifestation) from many angles for its best study in the current work and when designing works for subsequent surveys. One of the examples of such a model is the terricone surface of the former Kapitalnaya 1 mine (Fig. 2).

As can be seen from Figure 2, not only the 3D model was constructed, but also the terrain isohypses were calculated. The construction is based on the height map (Fig. 3), erroneous values are rejected at the post-processing stage (drawn up isohypses around buildings, structures, etc.), the frequency of isolines is determined manually and in this case the step is $5 \mathrm{~m}$. Based on the data obtained, it is possible to calculate the volume of waste rock contained in the dump. The measurement accuracy depends on the frequency of isolines. The volume calculation is based on 11 terrain isolines and is presented in Table 2 . 


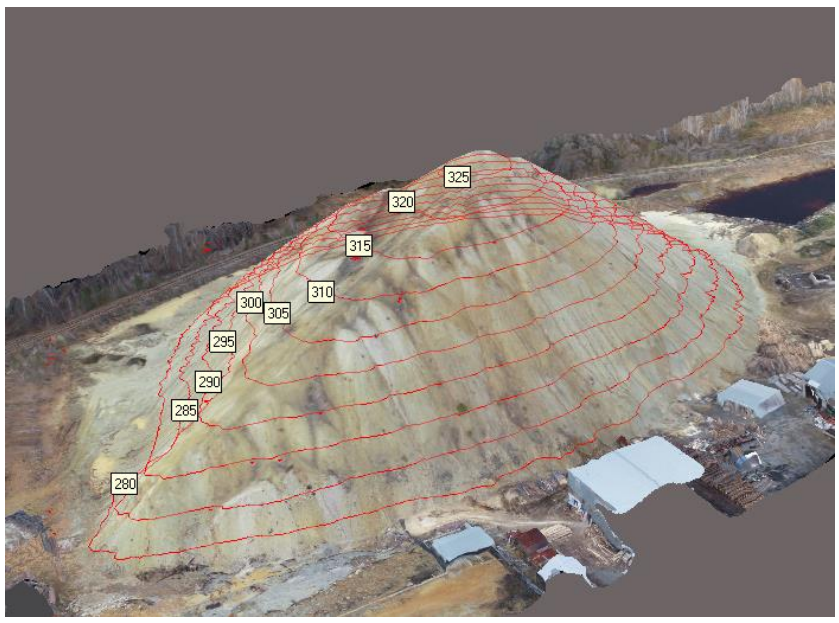

Fig. 2. 3D model of waste rock dump.

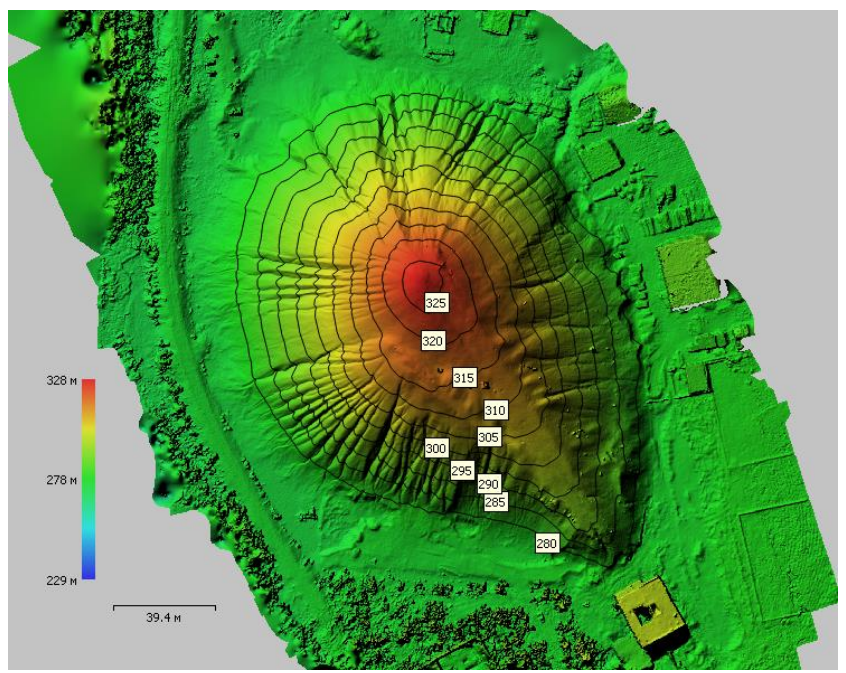

Fig. 3. The height map built on the basis of aerial photofixation by UAV.

Table 3. Font styles for a reference.

\begin{tabular}{|c|c|c|c|}
\hline $\begin{array}{c}\text { Absolute mark of } \\
\text { terrain isoline }\end{array}$ & $\begin{array}{c}\text { Area of each formation, } \\
\mathbf{~ m}^{\mathbf{2}}\end{array}$ & Isoline step, $\mathbf{~ m}$ & $\begin{array}{c}\text { Volume of each } \\
\text { formation, } \mathbf{~}^{\mathbf{3}}\end{array}$ \\
\hline 275 & 26993,90 & 5 & 134969,50 \\
\hline 280 & 20310,90 & 5 & 101554,50 \\
\hline 285 & 16787,10 & 5 & 83935,50 \\
\hline 290 & 13584,30 & 5 & 67921,50 \\
\hline 295 & 10763,70 & 5 & 53818,50 \\
\hline 300 & 8315,94 & 5 & 41579,70 \\
\hline 305 & 6187,55 & 5 & 30937,75 \\
\hline 310 & 4262,96 & 5 & 21314,80 \\
\hline 315 & 2556,79 & 5 & 12783,95 \\
\hline 320 & 1084,61 & 5 & 5423,05 \\
\hline 325 & 233,27 & 2,5 & 583,17 \\
\hline \multicolumn{4}{|c}{ Total estimated volume, $\mathbf{m}^{\mathbf{3}}$} \\
\hline \multicolumn{3}{|c}{} \\
\hline
\end{tabular}




\section{Conclusions}

In many cases, such information is difficult to obtain using standard instrumental methods, not only because of the large extent or complex form of the object's manifestation, but also because of the sufficiently high danger or instability of the manifestation [6,7]. In this case, it includes an unstable (crumbling) surface and fairly steep lifting angles. The calculated volume and shape of the terrain can be further compared with more recent images in the future, obtaining information about the dynamics of the destruction of the terricone surface.

This method is also relevant for measurements of dangerous EGPs [8], where the dynamics of the process can be traced when overlapping different-time images. The total amount of information obtained with the help of UAVs allows you to safely and with sufficient accuracy determine the depth, area, total volume of separate manifestations, the speed of their development, slope angles, including hard-to-reach areas, and in some cases, the use of UAVs is the only possible option for working on the territory due to inaccessibility or significant time costs. In addition to a fairly high speed of territory survey, this allows us to talk about the prospective use of UAVs in order to conduct work on the SMSC.

\section{References}

1. N. A. Fedoseeva, M. V. Zagvozdkin, Scientific J, Promising applications of unmanned aerial vehicles, 9 (22), 26 (2017)

2. O. L. Silva, F.H.R. Bezerra, R.P. Maia, C.L. Cazarin, Geomorphology, 295, 611 (2017)

3. P. Pecho, I. Škvareková, V. Ažaltovič, M. Bugaj, Transportation research procedia, 43, 328 (2019)

4. E. Spiridenko, N. B. Khakhulina, Innovative technologies and technical means for agriculture, 170 (2016)

5. D.V. Grigoriev, A.S. Vedernikov, Subsoil Use Problems, Results of the use of 3Delectrotomography for the search for karst voids in the conditions of a salt dump, 4 (23), 137 (2019)

6. N.L. Fazio, M. Perrotti, G.F. Andriani, F. Mancini, P. Rossi, C. Castagnetti, P. Lollino, Engineering Geology, 260 (2019)

7. J. Langhammer, B. Janský. J. Kocum, R.Minařík, Applied Geography, 98 (2018)

8. E.Zh. Garmaev, B.Z. Tsydypov, V.S. Batomunkuev, C. Batchulun, R. Zolmon, Monitoring the development of slope-type ravines of the Selenginsky middle mountains, 115-118 (2018) 